\title{
A Native Ternary Complex Trapped in Crystal Reveals the Catalytic Mechanism of a Retaining Glycosyltransferase**
}

\author{
David Albesa-Jové, Fernanda Mendoza, Ane Rodrigo-Unzueta, Fernando Gomollón-Bel, Javier O. \\ Cifuente, Saioa Urresti, Natalia Comino, Hansel Gómez, Javier Romero-García, José M. Lluch, \\ Enea Sancho-Vaello, Xevi Biarnés, Antoni Planas, Pedro Merino, Laura Masgrau, and Marcelo E. \\ Guerin*
}

\begin{abstract}
Glycosyltransferases (GTs) comprise a prominent family of enzymes that play critical roles in a variety of cellular processes including cell signaling, cell development and host-pathogen interactions. Glycosyl transfer can proceed with either 'inversion' or 'retention' of the anomeric configuration with respect to the reaction substrates and products. The elucidation of the catalytic mechanism of retaining GTs remains a major challenge. We report the first native ternary complex of a GT, that of the retaining glucosyl-3-phosphoglycerate synthase GpgS from Mycobacterium tuberculosis, in the presence of the sugar donor UDP-Glc, the acceptor substrate phosphoglycerate and the divalent cation cofactor, in a productive mode for catalysis. In combination with structural, chemical, enzymatic, molecular dynamics and quantummechanics/molecular-mechanics (QM/MM) calculations, we unravel its catalytic mechanism, providing a strong experimental support for a front-side, substrate assisted $S_{N}$ i-type reaction.
\end{abstract}

[*] Dr. D. Albesa-Jové, A. Rodrigo-Unzueta, Dr. J. O. Cifuente, Dr. S Urresti, N. Comino, E. Sancho-Vaello, Prof. M.E. Guerin Unidad de Biofísica, Consejo Superior de Investigaciones Científicas - Universidad del País Vasco/Euskal Herriko Unibertsitatea (CSIC-UPV/EHU) and Departamento de Bioquímica, Universidad del País Vasco, 48940 Leioa, Bizkaia (Spain) E-mail: mrcguerin@gmail.com

Dr. Laura Masgrau. Institut de Biotecnologia i de Biomedicina (IBB) Fernanda Mendoza, Prof. José M. Lluch, IBB and Departament de Química, Universitat Autònoma de Barcelona, 08193 Bellaterra (Spain). Dr. Hansel Gómez, IBB and Joint BSC-CRG-IRB Program in Computational Biology, IRB Barcelona, 08028 Barcelona (Spain).

Fernando Gomollón-Bel, and Prof. Pedro Merino

Laboratorio de Síntesis Asimétrica, Departamento de Síntesis y Estructura de Biomoléculas, Instituto de Síntesis Química y Catálisis Homogénea (ISQCH), Universidad de Zaragoza, CSIC, 50009 Zaragoza, Aragón (Spain)

Javier Romero, Dr. X. Biarnés, and Prof. A. Planas Laboratory of Biochemistry, Institut Químic de Sarrià, Universitat Ramon Llull, Via Augusta 390, 08017 Barcelona, (Spain)

Dr. D. Albesa-Jové and Prof. M.E. Guerin IKERBASQUE, 48013, Bilbao (Spain)

[**] This work was supported by the EU Contract HEALTH-F3-2011260872, MINECO Contract BIO2013-49022-C2-2-R, and the Basque Government (to M.E.G.); MINECO Contracts CTQ201124292 and CTQ2014-53144-P (to J.M.LL.) and "UAB - Banco Santander Program" (to L.M.); CTQ2013-44367-C2-1-P (to P.M.) and MINECO Contract BIO2013-49022-C2-1-R (to A.P). We thank the SLS, DLS and BioStruct-X project for granting access to synchrotron radiation facilities. We gratefully acknowledge Sonia López-Fernández and Pedro Arrasate (Unit of Biophysics, CSIC,UPV/EHU, Spain), Dr E. Ogando and Dr. T. Mercero (Scientific Computing Service UPV/EHU, Spain) for technical assistance. F.G.-B. and F.M. acknowledge the support from JAE Predoc Program (CSIC) and "Becas de Doctorado en el Extranjero Becas Chile - CONICYT" Program, respectively.

Supporting information for this article is available on the WWW under http://dx.doi.org/10.1002/anie.201xxxxxx)
Glycosyltransferases (GTs) play a central role in nature. GTs catalyze the transfer of a sugar moiety from nucleotide-sugar or lipid-phospho-sugar donors to a wide range of acceptor substrates, including mono-, oligo-, and polysaccharides, lipids, proteins, small organic molecules and nucleic acids. ${ }^{[1,2]}$ As a consequence, GTs generate a significant amount of structural diversity in biological systems which is particularly apparent not only in the maintenance of the structural integrity of the cell but also in the modulation of molecular recognition events, including cell signaling, cell-cell communication, and cell-pathogen interactions. ${ }^{[3]}$ GTs can be classified into either 'inverting' or 'retaining' enzymes according to the anomeric configuration of the reaction substrates and products (Figure S1) ${ }^{[1]}$ The reaction mechanism of 'inverting' GTs seem to follow a single-displacement mechanism with an oxocarbenium ionlike transition state and an asynchronous $\mathrm{S}_{\mathrm{N}} 2$ mechanism, analogous to that observed for inverting glycosyl hydrolases. ${ }^{[1]}$ In contrast, the catalytic mechanism for 'retaining' GTs is currently a matter of strong debate. By analogy with glycosyl hydrolases, a double displacement mechanism via the formation of a covalent glycosylenzyme intermediate was first suggested. Such a mechanism would involve an enzymatic nucleophile positioned within the active site on the $\beta$-face of the donor substrate in close proximity to the anomeric reaction center (Figure 1A). Supporting this notion, the chemical rescue of the mammalian $\alpha-(1 \rightarrow 3)$-galactosyltransferase Glu317Ala mutant by sodium azide has been reported. ${ }^{[4]}$ The product of the chemical rescue resulted to be the inverted version of the sugar azide, which would be consistent with the first step in a double displacement mechanism. More recently, molecular dynamics simulations and density functional theory (DFT) Quantum Mechanics/Molecular Mechanics (QM/MM) calculations also confirmed the formation of a covalent glycosyl-enzyme intermediate in the enzyme. ${ }^{[5,6,7]}$ Covalent intermediates were also detected for the human blood group synthesizing $\alpha-(1 \rightarrow 3)-N-$ acetylgalactosaminyltransferase (GTA) and $\alpha-(1 \rightarrow 3)$ galactosyltransferase (GTB) mutants by mass spectrometry. ${ }^{[8,9]}$ However, in the absence of a residue near the reaction center that could act as a nucleophile to form the glycosyl-enzyme intermediate, an alternative mechanism known as the $\mathrm{S}_{\mathrm{N}} \mathrm{i}$ 'internal return', also called the ' $\mathrm{S}_{\mathrm{N}} \mathrm{i}$-like mechanism', has been suggested (Figure 1A). ${ }^{[1}$ ${ }^{10,11,12]}$ The concept of a general internal nucleophilic substitution mechanism $\mathrm{S}_{\mathrm{N}} \mathrm{i}$, which is neither simply $\mathrm{S}_{\mathrm{N}} 1$ nor $\mathrm{S}_{\mathrm{N}} 2$, was first invoked to explain unusual stereochemical outcomes of simple alkyl halides, and then proposed for glycosyl transfer mechanism, in the absence of any enzyme, to explain the retention of anomeric stereochemistry in the solvolysis of $\alpha$-glucosyl fluoride by mixtures of ethanol and trifluorethanol. ${ }^{[10]}$ In this mechanism leaving group 
departure and nucleophilic attack occur on the same face of the sugar [13], involving either a short-lived oxocarbenium ion intermediate $\left(\mathrm{S}_{\mathrm{N}} \mathrm{i}-\mathrm{like}\right)^{[6,9,14,15,16]}$ or an oxocarbenium ion transition state $\left(\mathrm{S}_{\mathrm{N}} \mathrm{i}\right)$. ${ }^{[17]}$

Figure 1. A. Proposed catalytic mechanisms for enzymatic glycosyl transfer with retention of the anomeric configuration: double displacement mechanism (1) and frontface mechanism (2) B. Overall structure of GpgS in complex with UDP-Glc and PGA.

A Covalent intermediate

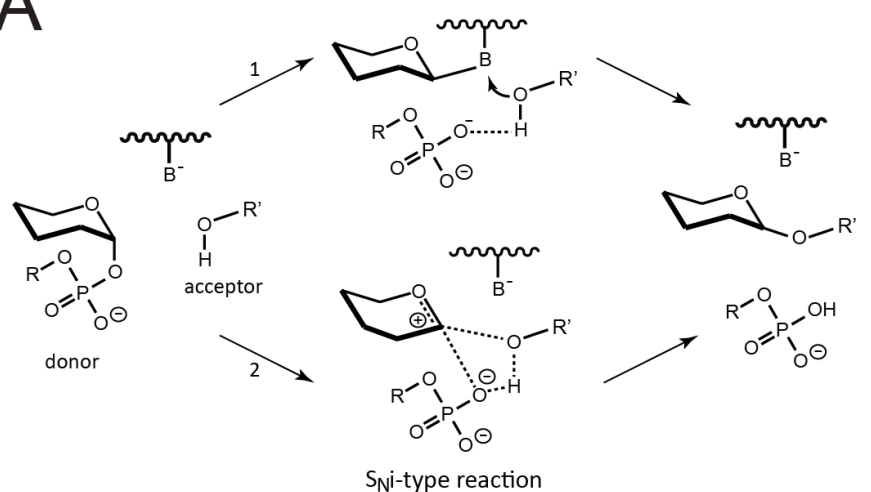

$\mathrm{B}$

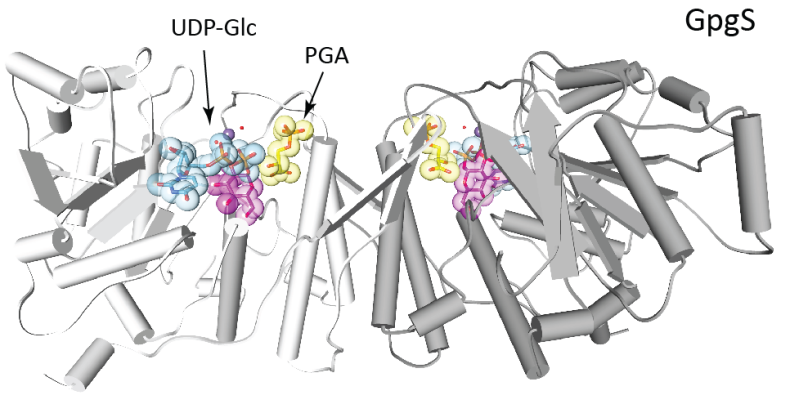

To further advance on the understanding of the catalytic mechanism of retaining glycosyl transfer reactions we investigated the glucosyl-3-phosphoglycerate synthase (GpgS) from Mycobacterium tuberculosis. GpgS is a retaining glucosyltransferase that initiates the biosynthetic pathway of 6-Omethyl glucose lipopolysaccarides (MGLPs) in mycobacteria, by transferring a Glc moiety from UDP-Glc to the 2 position of the phosphoglycerate (PGA) to form glucosyl-3-phosphoglycerate (Figure 1B and S2). [18, 19] MGLPs are cytoplasmic lipopolysaccharides of intermediate size containing up to $20 \mathrm{Glc}$ units, many of which are 6-O-methylated. MGLPs can be further acylated with additional acetyl, propionyl, isobutyryl, succinyl, and octanoyl groups. They have been postulated to regulate fatty acid metabolism due to their ability to form stable 1:1 complexes with fatty acyl chains. ${ }^{[18,19]}$ As most of the members of the GT-A superfamily of GTs, GpgS uses a divalent cation as an essential cofactor for enzymatic activity. Kinetic studies demonstrated that the enzyme prefers $\mathrm{Mg}^{2+}$ for maximal activity in vitro. However, GpgS was less but still enzymatically active when another group II metal ion $\left(\mathrm{Ca}^{2+}\right)$ and transition metal ions $\left(\mathrm{Mn}^{2+}, \mathrm{Co}^{2+}\right.$, and $\left.\mathrm{Fe}^{2+}\right)$ were introduced in the reaction mixture. ${ }^{[18]}$ The strategy to capture a native ternary complex $\mathrm{GpgS} \cdot \mathrm{Mn}^{2+} \cdot \mathrm{UDP}-\mathrm{Glc} \cdot \mathrm{PGA}$ was to carry out quick soak experiments of unliganded GpgS with the sugar donor UDP-Glc, the acceptor substrate PGA, in the presence of $\mathrm{Mn}^{2+}$ at different time points. Thus, we have obtained three snapshots of the reaction center at a resolution of $2.3 \AA, 2.3 \AA$ and $2.6 \AA$, providing for the first time the atomic coordinates of a native Michaelis complex for a GT in the absence of any substrate derivative or protein mutant (Figure 2, Table S1; Figure S5, see SI for details).

\section{Angewandte} Communications

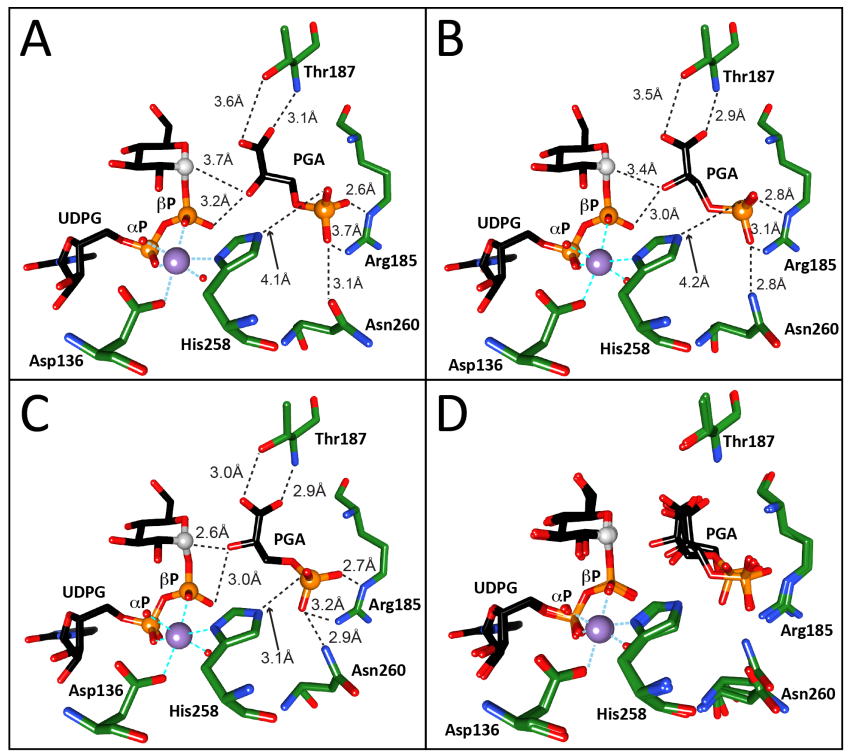

Figure 2. Three snapshots of the reaction center as visualized in the crystal structures of ternary complexes: GpgS $\bullet \mathrm{Mn}^{2+} \cdot \mathrm{UDP}-\mathrm{Gl} \cdot \mathrm{PGA}-3$ (A, 4Y9X), GpgS $\bullet \mathrm{Mn}^{2+} \cdot \mathrm{UDP}-$ Glc $\bullet$ PGA-2 (B, pre-Michaelis complex, 4Y6U), and GpgS• $\mathrm{Mn}^{2+} \bullet \mathrm{UDP}-\mathrm{Glc} \bullet \mathrm{PGA}-1$ (C, Michaelis complex, $4 \mathrm{Y} 6 \mathrm{~N}$ ). D) Structural comparison of a selected region of the active site in the GpgS $\bullet \mathrm{Mn}^{2+} \cdot \mathrm{UDP}-\mathrm{Glc} \cdot \mathrm{PGA}-1, \quad \mathrm{GpgS} \cdot \mathrm{Mn}^{2+} \cdot \mathrm{UDP}-\mathrm{Glc} \cdot \mathrm{PGA}-2$ and $\mathrm{GpgS} \cdot \mathrm{Mn}^{2+} \cdot \mathrm{UDP}-\mathrm{Glc} \cdot \mathrm{PGA}-3$ complexes.

GpgS is a homodimer, with each monomer displaying a well defined and positively charged tunnel, compatible with the binding of phosphate-containing substrates such as UDP-Glc and PGA (Figure 1B). ${ }^{[18]}$ This tunnel is shaped in the form of two opposing funnels, separated by a flexible loop that seems to modulate substrate binding and playing a critical role during the catalytic cycle. ${ }^{[18]}$ Both UDP-Glc and PGA substrates and the cofactor are clearly visible in the electron density maps, and are located on the center of the tunnel where the glucose transfer reaction takes place (Figure S4). Importantly, the close inspection of the active site of GpgS revealed the lack of a putative nucleophile residue that could result in the formation of a glycosyl-enzyme covalent intermediate. Therefore, it is expected that the reaction catalyzed by GpgS would proceed via a front-side, substrate assisted SNi-type mechanism. The first step in such reaction would be the breaking of the glucosidic $\mathrm{O}_{\mathrm{P}}-\mathrm{C} 1$ ' bond, accounting for most of the activation energy, and facilitated by a critical stabilizing interaction of the acceptor hydrogen atom $\mathrm{O} 3$ of the acceptor PGA with the $\beta$ phosphate of the nucleotide sugar. Interestingly, in the first crystal structure $\left(\mathrm{GpgS} \bullet \mathrm{Mn}^{2+} \cdot \mathrm{UDP}-\mathrm{Glc} \cdot \mathrm{PGA}-3\right.$, pdb code $\left.4 \mathrm{Y} 9 \mathrm{X}\right)$, the acceptor oxygen atom $\mathrm{O} 3$ of PGA places at a wide distance of $3.7 \AA$ from the anomeric carbon $\mathrm{C} 1$ ' of the sugar and at $3.2 \AA$ of the $\mathrm{O} 1 \mathrm{~B}$ atom of the $\beta$-phosphate (Figure $2 \mathrm{~A}$ ). In a second crystal structure $\left(\mathrm{GpgS} \cdot \mathrm{Mn}^{2+} \cdot \mathrm{UDP}-\mathrm{Glc} \cdot \mathrm{PGA}-2\right.$, pdb code $\left.4 \mathrm{Y} 6 \mathrm{U}\right)$, a pre-Michaelis complex shows the anomeric carbon $\mathrm{C} 1$ ' of the sugar at $3.4 \AA$ from the acceptor oxygen atom $\mathrm{O} 3$ of PGA. The O1B atom of the $\beta$ phosphate is at $3.0 \AA$ of the $\mathrm{O} 3$ atom of PGA (Figure 2B). In the Michaelis complex $\left(\mathrm{GpgS} \bullet \mathrm{Mn}^{2+} \cdot \mathrm{UDP}-\mathrm{Glc} \cdot \mathrm{PGA}-1\right.$, pdb code $\left.4 \mathrm{Y} 6 \mathrm{~N}\right)$ the anomeric carbon $\mathrm{C} 1$ ' of the sugar approaches now at only $2.6 \AA$ from the acceptor oxygen atom $\mathrm{O} 3$ of PGA, which in turn hydrogen bonds with the O1B atom of the $\beta$-phosphate (Figure 2C and 2D). Thus, the configuration of the active site in the native Michaelis complex of GpgS for the wild type enzyme and with the natural substrates provides strong experimental evidence in support of such mechanism. 
Two additional ternary complexes provide significant insight not only in the binding mode of the sugar donor and acceptor substrates to the active site, but also into the catalytic mechanism of GpgS (Table S1; Figure 3 and S6). The first complex was solved with UDP-Glc, 3-(phosphonooxy)propanoic acid (PPA), an analogue of PGA lacking the glucose-accepting hydroxyl group, and $\mathrm{Mn}^{2+}$ as a divalent cation (Figure $3 \mathrm{~A}$; GpgS $\bullet \mathrm{Mn}^{2+} \cdot \mathrm{UDP}-\mathrm{Glc} \bullet \mathrm{PPA}$; pdb code 4Y7F). We confirmed that the enzyme was unable to transfer a Glc residue to PPA (see SI for details). The carboxyl group of PPA superimposes well with the corresponding moiety of PGA as observed in the ternary complex GpgS $\bullet \mathrm{Mn}^{2+} \cdot \mathrm{UDP}-\mathrm{Glc} \cdot \mathrm{PGA}-1$. However, C2, C3 and the phosphate moiety adopt a different conformation (Figure 2; r.m.s.d. of $0.9 \AA$ ). As expected, there is no electron density that could indicate the formation of a covalent adduct between the GT and the glucose moiety in the GpgS $\bullet \mathrm{Mn}^{2+} \cdot$ UDP-Glc $\bullet P P A$ complex. The second complex was solved with UDP-Glc, glycerol 3-phosphate (G3P), an analogue of PGA in which the carboxyl group is replaced by a hydroxyl group, and $\mathrm{Mn}^{2+}$ as a divalent cation (Figure $3 \mathrm{~B}, \mathrm{GpgS} \cdot \mathrm{Mn}^{2+} \cdot \mathrm{UDP}-$ Glc $\bullet$ G3P; pdb code $4 \mathrm{Y} 7 \mathrm{G})$. The phosphate group of PGA, hydrogen bonds with the lateral chains of Arg185 and Asn260, as previously visualized in the $\mathrm{GpgS} \cdot \mathrm{Mn}^{2+} \cdot \mathrm{UDP}-\mathrm{Glc} \cdot \mathrm{PGA}-1$ and $\mathrm{GpgS} \bullet \mathrm{Mn}^{2+} \cdot \mathrm{UDP}-\mathrm{Glc} \cdot \mathrm{PPA}$ complexes. However, the rest of the G3P molecule displays a different structural arrangement (r.m.s.d. of $2.5 \AA$ ). Specifically, the oxygen atom O2 of G3P, equivalent to the acceptor oxygen atom $\mathrm{O} 3$ of PGA, moves away from the glucose moiety making new electrostatic interactions with the guanidinium group of Arg256, and the lateral chain of His258. The oxygen atom O1 makes hydrogen bond with the side chain OG1 atom of Thr187 residue (Figure 3B). Altogether the experimental data strongly support the carboxyl moiety of PGA playing a key role in the generation of a competent reaction center for GpgS.

Figure 3. The catalytic site as visualized in the crystal structures of the ternary complexes GpgS $\bullet \mathrm{Mn}^{2+} \cdot \mathrm{UDP}-\mathrm{Glc} \cdot \mathrm{PPA}(\mathrm{A}, 4 \mathrm{Y} 7 \mathrm{~F})$, and $\mathrm{GpgS} \bullet \mathrm{Mn}^{2+} \cdot \mathrm{UDP}-\mathrm{Gl} \bullet \mathrm{G} 3 \mathrm{P}(\mathrm{B}$,

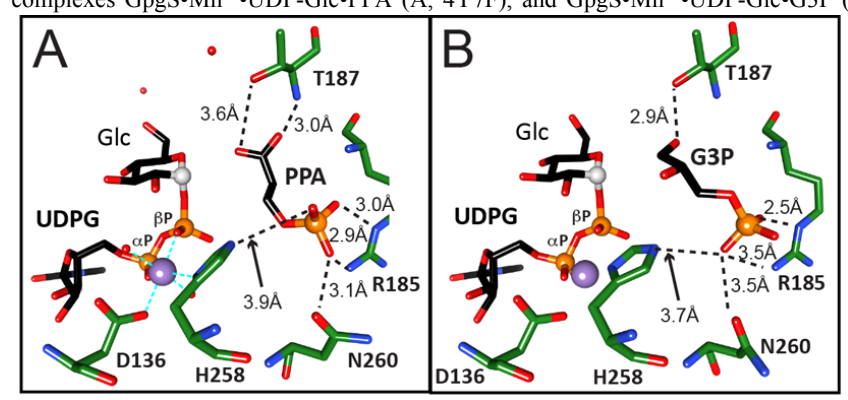

4Y7G).

To further investigate the importance of the carboxyl moiety of PGA, we synthesized a PGA derivative in which the carboxyl group was replaced by amide (PGD; see details in SI Section). Interestingly, PGD, as G3P, could not serve as an acceptor of Glc, although it contains the oxygen atom $\mathrm{O} 3$ of PGA (see SI section for details). In addition, despite much effort, we were unable to crystallize GpgS in complex with the PGD derivative, even by soaking or co-crystallization experiments. A plausible reason is that the carboxyl O2 of PGA makes a strong hydrogen bond with the main chain amino group of $\mathrm{Thr} 187$ in the $\mathrm{GpgS} \cdot \mathrm{Mn}^{2+} \cdot \mathrm{UDP}-$ Glc $\bullet$ PGA-1. Thus, the presence of an amide group in PGD might lead to an electrostatic repulsion with Thr187, preventing its binding to GpgS.

The experimental native Michaelis complex of GpgS is in good agreement with the predicted Michaelis complexes of the lipopolysaccharyl- $\alpha$-1,4-galactosyltransferase $\left.C(\operatorname{LgtC})^{[11,} 17\right]$, the trehalose-6-phosphate synthase $(\mathrm{OtsA})^{[15,20]}$, and the recently

\section{Angewandte Communications}

obtained for the polypeptide $N$-acetylgalactosaminyltransferase 2, containing the UDP-GalNAc derivative UDP-5SGalNAc and the truncated incompetent mEA2 peptide STCPA (GalNAc-T2; Figure S7). ${ }^{[16]}$ The LgtC Michaelis complex was modeled based on a crystal structure containing two substrate analogues, UDP 2-deoxy2'-F-Gal and 4-deoxylactose. The attacking hydroxyl group of lactose has the oxygen atom $\mathrm{O} 4$ at a distance of $3.1 \AA$ from the anomeric carbon $\mathrm{C}^{\prime}$ of the donor galactose moiety, and at $2.7 \AA$ from the glycosidic oxygen atom. Moreover, the $\mathrm{O} 3$ of the acceptor lactose is also hydrogen bonded to the $\beta$-phosphate of UDP, thus stabilizing leaving group departure. ${ }^{[17]}$ The OtsA Michaelis complex was constructed based on its complex with UDP and validoxylamine-6-phosphate (VA6P), a compound that structurally resembles to one of the reaction products, trehalose-6-phosphate. The anomeric carbon $\mathrm{C}$ of the Glc moiety is at $3.0 \AA$ from the O1' of the Glc-6-phosphate acceptor. ${ }^{[15]}$ In GalNAc-T2, the hydroxyl oxygen atom OG1 of the acceptor Thr is at $2.5 \AA$ to the anomeric carbon $\mathrm{C} 1$ ' of the GalNAc moiety, and at 2.7 and $3.6 \AA$ of the two $\beta$-phosphate oxygen atoms of UDP moiety. ${ }^{[16]}$ In addition, the backbone amide of the acceptor Thr is also hydrogen bonded with the $\beta$-phosphate. ${ }^{[21]}$ Similarly, the acceptor oxygen atom $\mathrm{O} 3$ of the acceptor PGA places at $2.6 \AA$ to the anomeric carbon $\mathrm{C} 1$ ' of the Glc residue in GpgS, and at 2.4 and $3.0 \AA$ of the corresponding $\beta$ phosphate oxygen atoms of the UDP moiety. No other interactions are observed between donor and acceptor substrates in GpgS. Extensive theoretical studies using QM/MM calculation simulations supported the occurrence of the $\mathrm{S}_{\mathrm{N}} \mathrm{i}$ 'internal return' mechanism in OtsA, LgtC and GalNAc-T2. ${ }^{[15,16,17,21]}$

We have employed molecular dynamics simulations combined with QM(DFT)/MM calculations to further understand the reaction mechanism followed by GpgS (see SI Section for details; Figure 4 and S9). The sugar transfer was modeled using the reaction coordinate $\mathrm{RC}=\left[d\left(\mathrm{O}_{\mathrm{P}}-\mathrm{C} 1^{\prime}\right)-d\left(\mathrm{O}_{\mathrm{PGA}}-\mathrm{C} 1^{\prime}\right)-d\left(\mathrm{HO}_{\mathrm{PGA}}-\mathrm{O}_{\mathrm{P}}\right)\right]$ to drive the system from reactants to products, at a $\mathrm{QM}(\mathrm{DFT}) / \mathrm{MM}$ level of theory that we have successfully applied in other retaining GTs. ${ }^{[6,17,21]}$ Two transition states (TS1 and TS2) and a short-lived ion pair intermediate (IP) connecting them were found (Figure 4 and Table S2), so that an asynchronous mechanism is obtained. As depicted in Figure 4, the reaction starts with the $\mathrm{O}_{\mathrm{P}}-\mathrm{HO}_{\mathrm{PGA}}$ hydrogen bond getting shorter (by $\sim 0.4 \AA, \mathrm{RC}=-3.6 \AA$ ). This interaction between donor and acceptor substrates is recurrent in all 'retaining' GTs studied to date, and seems to be essential in facilitating nucleotide-sugar bond breakage (substrate-assisted catalysis). Then, the TS1 is reached, in which the $\mathrm{O}_{\mathrm{P}}-\mathrm{C1}$ ' distance increases up to $2.68 \AA$, the $\mathrm{HO}_{\mathrm{PGA}}$ is at $1.65 \AA$ from the $\mathrm{O}_{\mathrm{P}}$, and the $\mathrm{O} 3_{\mathrm{PGA}}-\mathrm{C} 1$ ' distance shortens to $2.62 \AA$. The breakage of the UDPGlc bond results in a positive charge increase of $\Delta q\left(\mathrm{C} 1^{\prime}+\mathrm{H} 1^{\prime}+\mathrm{O} 5\right.$ ') $=0.36$ a.u. at the anomeric centre (Table S2). Importantly, the ring conformation changes from a ${ }^{4} \mathrm{C}_{1}$ chair in the reactants to a ${ }^{4} \mathrm{E}$ half chair in TS1, with the $\mathrm{C1}$ '- O5' distance getting a double-bond character (Table S2). The energy cost to reach TS1 is of 21.4 $\mathrm{kcal} / \mathrm{mol}$. After TS1, the energy along the reaction coordinate decreases by $\sim 2 \mathrm{kcal} / \mathrm{mol}$ and a short-lived oxocarbenium intermediate is formed (sugar ring conformation between ${ }^{4} \mathrm{E}$ and ${ }^{4} \mathrm{H}_{5}$ ). In this IP, the glucosidic bond is definitely broken (the $\mathrm{O}_{\mathrm{P}}-\mathrm{C} 1{ }^{\prime}$ distance is now of $3.20 \AA$ ), whereas the $\mathrm{HO}_{\mathrm{PGA}}-\mathrm{O} 3_{\mathrm{PGA}}$ and the $\mathrm{C} 1$ '- O5' distances remain practically invariant with respect to TS1. The attacking $\mathrm{O}_{\mathrm{PGA}_{\mathrm{PA}}}$ atom gets $0.3 \AA$ closer of $\mathrm{C} 1$ '. The energy of the optimized IP is $0.6 \mathrm{kcal} / \mathrm{mol}$ lower than that of TS1. From the IP, the acceptor attack takes place through TS2, where the $\mathrm{C} 1{ }^{\prime}-{ }^{-} 3_{\mathrm{PGA}}$ and $\mathrm{HO}_{\mathrm{PGA}}-\mathrm{O}_{\mathrm{P}}$ distances are of $2.26 \AA$ and $1.56 \AA$, respectively. TS2 lays $21.8 \mathrm{kcal} / \mathrm{mol}$ above the Michaelis complex, and 0.5 $\mathrm{kcal} / \mathrm{mol}$ above the IP. Thus, most of the overall energy barrier for 
the transfer reaction to take place is due to glucosidic $\mathrm{O}_{\mathrm{P}}-\mathrm{C} 1^{\prime}$, bond dissociation. These energies indicate that the IP could be a very short-lived species with no time to thermally equilibrate. The calculated rate-limiting energy barrier $(21.9 \mathrm{kcal} / \mathrm{mol})$ is in reasonable agreement with the experimentally derived phenomenological free energy of activation of $17.5 \mathrm{kcal} / \mathrm{mol}$, derived from a $\mathrm{k}_{\mathrm{cat}}$ value of $800 \mathrm{~min}^{-1}$ (see SI for details), supporting that $\mathrm{GpgS}$ follows a front-side attack mechanism.

Intriguingly, the active site of a few GTs displays a carboxylate residue allowing the enzyme to follow a double-displacement reaction, ${ }^{[6,7,9]}$ whereas most of retaining GTs, in the absence of such nucleophile, seems to follow a front-side mechanism. We propose
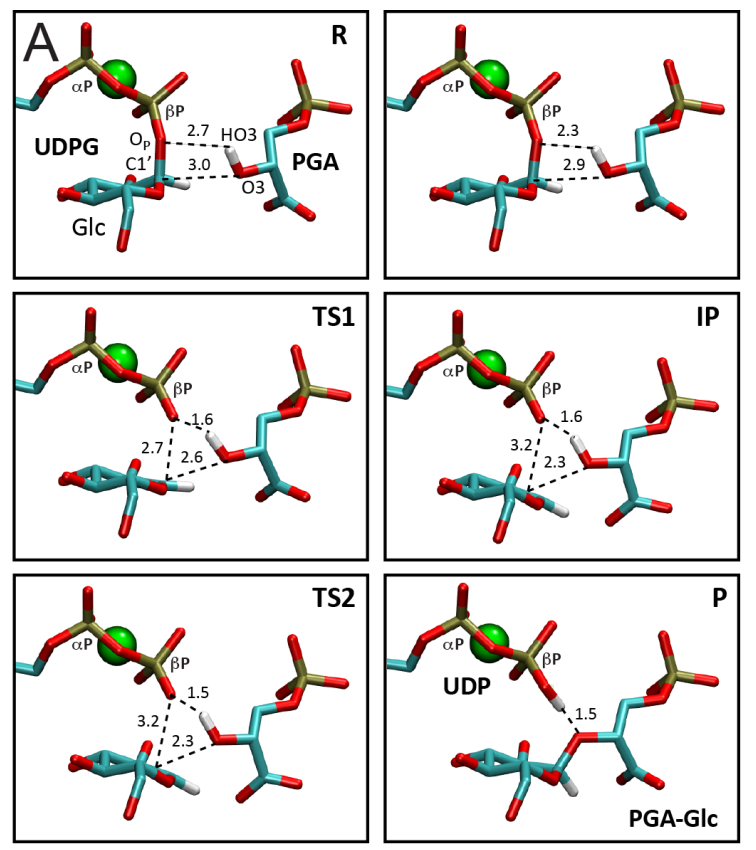

B
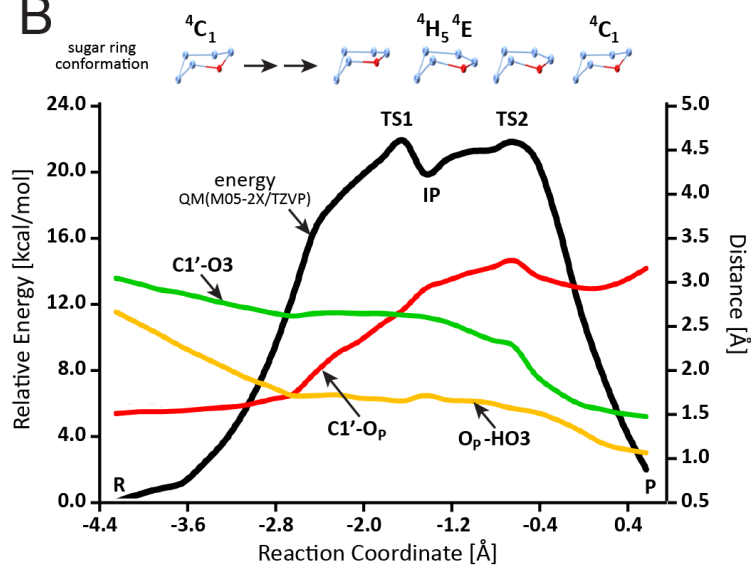

Figure 4. A. The atomic rearrangement along the reaction pathway in GpgS: reactants (R), structure at $\mathrm{RC}=-3.6 \AA$, transition state 1 (TS1), ion-pair intermediate (IP), transition state 2 (TS2) and products. B. Structural and energetics of the reaction coordinate.

Received: ((will be filled in by the editorial staff)) Published online on ((will be filled in by the editorial staff))

Keywords: glycosyltransferase $\bullet$ structure $\bullet$ enzymesubstrate complex $\bullet$ catalysis $\bullet$ front side reaction

[1] L. L. Lairson, B. Henrissat, G. J. Davies, S. G. Withers, Annu. Rev. Biochem. 2008, 77, 521-555.

\section{Angewandte Communications}

that both mechanisms might represent a different manner to stabilize the oxocarbenium-ion-like species that forms upon cleavage of the donor sugar-phosphate bond. In $\mathrm{GpgS}$, the electrostatic potential at the reaction center can stabilize the oxocarbenium-ion like intermediate for a very short period of time, allowing the active site to reorganize and the oxocarbenium-ion species and the acceptor to move one towards the other. By contrast, in the $\alpha-1,3-$ galactosyltransferase GTB (blood group galactosyltransferase) ${ }^{[22]}$ or the $N$-acetyllactosaminide $\alpha$-1,3-galactosyl transferase $\alpha 3 \mathrm{GalT}^{[23]}$, the oxocarbenium-ion-like transition state is stabilized by the formation of a covalent bond with the nucleophile residue present in these enzymes. Thus, both modes of operation could be considered as variations of a common mechanism, a two steps reaction via oxocarbenium-ion-like-transition states that flank an intermediate, either an oxocarbenium ion or a covalent glycosyl-enzyme depending of the active site configuration.

[2] D. Albesa-Jové, D. Giganti, M. Jackson, P. M. Alzari, M. E. Guerin, Glycobiology 2014, 24, 108-124.

[3] A. Varki, Essentials of Glycobiology, 2nd ed. (Eds.: A. Varki, R. Cummings, J. Esko, H. Freeze, P. Stanley, C. R. Bertozzi, G. Hart, M. E. Etzler) Cold Spring Harbor Laboratory Press, ColdSpring Harbor, NY, 2009

[4] A. Monegal, A. Planas, J. Am. Chem. Soc. 2006, 128, 16030-16031.

[5] H. Gómez, J. M. Lluch, L. Masgrau, Carbohdr. Res. 2012, 356, $204-$ 208.

[6] H. Gómez, J. M. Lluch, L. Masgrau, J. Am. Chem. Soc. 2013, 135, 7053-7063.

[7] V. Rojas-Cervellera, A. Ardèvol, M. Boero, A. Planas, C. Rovira, Chemistry 2013, 19, 14018-14023.

[8] N. Soya, Y. Fang, M. M. Palcic, J. S. Klassen, Glycobiology 2011, 21 , 547-552.

[9] A. Bobovská, I. Tvaroška, J. Kóňa, Glycobiology 2015, 25, 3-7.

[10] M. L. Sinnott, W. P. Jencks, J. Am. Chem. Soc. 1980, 102, 2026-2032.

[11] K. Persson, H. D. Ly, M. Dieckelmann, W. W. Wakarchuk, S. G. Withers, N. C. Strynadka, Nat. Struct. Biol. 2001, 8, 166-175.

[12] R. P. Gibson, J. P. Turkenburg, S. J. Charnock, R. Lloyd, G. J. Davies, Chem. Biol. 2002, 9, 1337-1346.

[13] S. S. Lee, S. Y. Hong, J. C. Errey, A. Izumi, G. J. Davies, B. G. Davis, Nat. Chem. Biol. 2011, 7, 631-638.

[14] A. Bobovská, I. Tvaroška, J. Kóňa, Org. Biomol. Chem. 2014, 12, 4201-4210.

[15] A. Ardèvol, C. Rovira, Angew Chem Int Ed Engl. 2011, 50, $10897-$ 10901.

[16] E. Lira-Navarrete, J. Iglesias-Fernández, W. F. Zandberg, I. Compañón, Y. Kong, F. Corzana, B. M. Pinto, H. Clausen, J. M. Peregrina, D. J. Vocadlo, C. Rovira, R. Hurtado-Guerrero, Angew Chem Int Ed Engl. 2014, 53, 8206-8210.

[17] H. Gómez, I. Polyak, W. Thiel, J. M. Lluch, L. Masgrau, J. Am. Chem. Soc. 2012, 134, 4743-4752.

[18] S. Urresti, D. Albesa-Jové, F. Schaeffer, H. T. Pham, D. Kaur, P. Gest, M. J. van der Woerd, A. Carreras-González, S. López-Fernández, P. M. Alzari, P. J. Brennan, M. Jackson, M. E. Guerin, J. Biol. Chem. 2012, 287, 24649-24661.

[19] M. Jackson, P. J. Brennan, J. Biol. Chem. 2009, 284, 1949-1953.

[20] J. C. Errey, S. S. Lee, R. P. Gibson, C. Martinez Fleites, C. S. Barry, P. M. Jung, A. C. O'Sullivan, B. G. Davis, G. J. Davies, Angew Chem Int Ed Engl. 2010, 49, 1234-1237.

[21] H. Gómez, R. Rojas, D. Patel, L. A. Tabak, J. M. Lluch, L. Masgrau, Org. Biomol. Chem. 2014, 12, 2645-2655.

[22] J. A. Alfaro, R. B. Zheng, M. Persson, J. A. Letts, R. Polakowski, Y. Bai, S. N. Borisova, N. O. Seto, T. L. Lowary, M. M. Palcic, S. V. Evans, J. Biol. Chem. 2008, 283, 10097-10108.

[23] E. Boix, Y. Zhang, G. J. Swaminathan, K. Brew, K. R. Acharya, J. Biol. Chem. 2002, 277, 28310-28318 


\section{Angewandte \\ Communications}

Entry for the Table of Contents (Please choose one layout)

Layout 2:

\section{COMMUNICATION}

A native ternary complex of a glycosyltransferase, that of the retaining glucosyl-3-

phosphoglycerate synthase Gpgs in a productive mode for catalysis, was obtained for the first time. In combination with structural, chemical, enzymatic, molecular dynamics and quantummechanics/molecular-mechanics (QM/MM) calculations, we unravel its catalytic mechanism, providing strong experimental support for a front-side, substrate assisted $\mathrm{S}_{\mathrm{N}} \mathrm{i}$ type reaction.

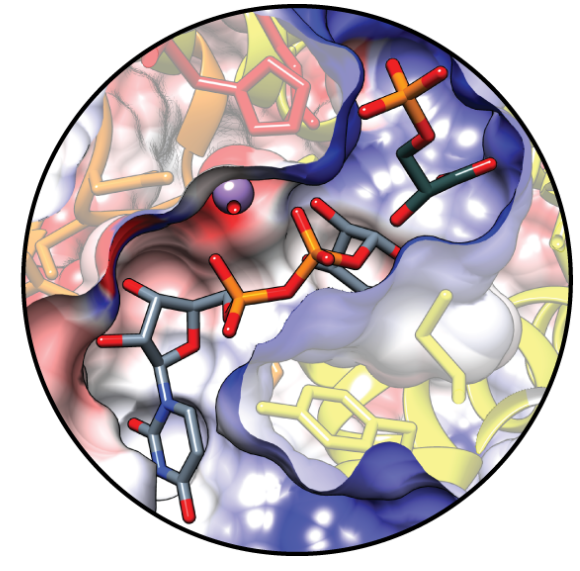

David Albesa-Jové, Fernanda Mendoza, Ane Rodrigo-Unzueta, Fernando Gomollón-Bel, Javier O. Cifuente, Saioa Urresti, Natalia Comino, Hansel Gómez, Javier Romero-García, José M. Lluch, Enea Sancho-Vaello, Xevi Biarnés, Antoni Planas, Pedro Merino, Laura Masgrau, and Marcelo E. Guerin*

Page No. - Page No. 